\title{
Beach morphodynamic characteristics and classifications on the straight coastal sectors in the west Guangdong
}

\author{
DING Yuanting ${ }^{1},{ }^{*} Y U$ Jitao $^{2}$, CHENG Huangxin ${ }^{3}$ \\ 1. School of Environmental Studies, China University of Geosciences, Wuhan 430074, China; \\ 2. School of Surveying and Land Information Engineering, Henan Polytechnic University, Jiaozuo 454000, \\ Henan, China; \\ 3. Department of Landscape Architecture, China University of Geosciences, Wuhan 430074, China
}

\begin{abstract}
Currently beach morphodynamic classification is the most important foundation to conduct associated coastal geomorphological studies. This paper carried out beach morphodynamic classifications for 12 straight beaches on headland-bay coasts based on field survey and evaluated the applicability of the most widely used dimensional fall velocity parameter $(\Omega)$ and relative tidal range parameter $(R T R)$. One reflective, five intermediate and six non-barred dissipative beaches were visually classified and sand size seemed to be a key factor to differentiate these beaches. The studied beaches were in relatively low wave energy environments $\left(H_{s}<1 \mathrm{~m}\right)$ and the absolute deep-water wave energy level of $P_{0}=3 \mathrm{KWm}^{-1}$ was supposed to a critical threshold to characterize the applicability of the $\Omega$ and $R T R$ parameters. These two morphodynamic parameters were applicable for the beaches with $P_{0}>3 \mathrm{KWm}^{-1}$ and $M S R<2 \mathrm{~m}$. It was found that the model of the traditional winter-and-summer profiles was not applicable in the study area in despite of distinct wave seasonality. The studied beaches were more possible to hover around a limited range due to relatively low background wave environments and variability without considering typhoon impacts, which needs further research on actual breaker wave conditions and beach morphodynamic type responses to typhoon events.
\end{abstract}

Keywords: beach morphodynamic type; dimensionless fall velocity; relative tidal range; wave power level; straight beaches

\section{Introduction}

Beach morphodynamic classifications have been received general acceptance in the geological and geomorphological literature (e.g., Wright and Short, 1984; Masselink and Short,

Received: 2019-03-21 Accepted: 2019-09-09

Foundation: National Science Foundation of China, No.41301005, No.41701011; Postdoctoral Science Foundation of China, No.2014M552118; China Scholarship Council, No.201608410419

Author: Ding Yuanting, PhD, specialized in coastal environment. E-mail: dytmtt@163.com

*Corresponding author: Yu Jitao, $\mathrm{PhD}$ and Associated Professor, specialized in coastal geomorphology. E-mail: ddyjt@163.com 
1993; Gómez-Pujol et al., 2007; Sénéchal et al., 2009; Scott et al., 2011; Aleman et al., 2015; Veas et al., 2017). Beach morphodynamic types within the beach morphodynamic framework relate with many beach aspects, such as morphological variation (Short, 1978, 1979; Wright and Short, 1984; Short and Aagaard, 1993; Aleman et al., 2015), surf zone processes (Wright et al., 1979; Wright and Short, 1984; Masselink and Short, 1993), swash regime (Hughes et al., 1997, 2014; Silva et al., 2018), dune occurrence (Short and Hesp, 1982), beach safety (Short and Hogan, 1994; Scott et al., 2009), beach ecology (Defeo and McLachlan, 2005, 2011), etc.

Earlier studies emphasized the seasonal beach evolution starting with two-dimensional beach profiles, and tried to relate several environmental parameters to morphological changes. As a classic model in beach studies, Shepard and LaFonda (1940) proposed the winter "bar" profile and the summer "berm" profile, but they could not explain the transition between the two types. The model is only applicable in the swell environment on the western coast in Northern Hemisphere and sheltered sea coast in mid-latitude region, and not suitable for the other coastal environments (Short, 1978). When annual variation in wave heights corresponds to beach morphological annual cycle, beaches will reach a complete periodic cycle from the winter storm profile to the summer berm profile. If the variance in annual wave heights is non-periodic, in other words, the waves do not remain small long enough for the summer profile or high waves are precluded by nearshore frictional dissipation for the winter profile, the annual cyclic transition for the two types of profiles cannot occur (Wright and Short, 1984). Hence, the model of the "storm-post-storm" profiles with a shorter temporal scale was further developed (e.g., Dubois, 1988; Stive et al., 2002). However, it is difficult by the two-dimensional beach profile variation to identify the inherent three-dimensional behavior of beach and surf zone. Therefore, a more general model of beach morphodynamic classifications is compulsory to link the two-dimensional variation with the three-dimensional behavior.

Wright and Short (1984) synthesized associated morphological studies of Short (1978, 1979) and hydrodynamic studies of Wright et al. (1979), and presented the most frequently occurring beach type (modal state) under a certain dynamical environment and the occurrence, morphology and dynamics, sediment transport, change rate and erosion pattern of reflective, intermediate and dissipative beaches, which build a foundation of contemporary beach studies. Meanwhile, they found the three beach types could be predicted and classified by the dimensionless fall velocity parameter $(\Omega)$ according to wave and sediment characteristics, defined as $\Omega=H_{b} / W_{s} T$ (in which $H_{b}$ is breaker height, $T$ is wave period, and $W_{s}$ is sediment fall velocity). When $\Omega$ is less than 1 , the beach is reflective; when $\Omega$ is more than 6 , the beach is dissipative; when $\Omega$ between 1 and 6 , the beach is one of the four intermediate types (Low Tide Terrace, Transverse Bar and Rip, Rhythmic Bar and Beach, and Longshore Bar and Trough). By means of $\Omega$, Masselink and Short (1993) presented the relative tide range $(R T R)$ parameter in order to incorporate the effect of tides on beach morphology, defined as $R T R=M S R / H_{b}$ (in which $M S R$ is mean spring tide range and $H_{b}$ is breaker height). This work not only included the wave-dominated, micro-tidal beach morphodynamic types (reflective, intermediate and dissipative), but extended to the wave-dominated, tide-modified beach types (low tide terrace with/without rips, low tide bar/rip, non-barred dissipative beach, and ultra-dissipative beach). Masselink and Short (1993) also pointed out that the 
wave energy level in their model was considered only in a relative way of waves versus tides, however, the absolute wave energy level was also of significance in determining beach morphological changes and the occurrence of three-dimensional morphologies (bars and rips). The three-dimensional beach morphologies do not occur if the wave energy level is too low to excite the formation of infragravity edge waves. In low-energy marine settings, beach morphodynamic types are often in disagreement with the prevailing wave conditions, which are inherited from previous high-energy events (Short, 1975; Costas et al., 2005).

Most of beach morphodynamic studies concerned the variation in beach profile data from several repeated observations in different regions in China (e.g., Li et al., 2012; Zhou et al., 2013; Tong et al., 2014; Cheng et al., 2015; Feng et al., 2016; Yu et al., 2016). These studies are site-specific and associated results cannot compare with each other, which may largely constrain the profundity of beach morphodynamics. Some existing studies noticed the importance of beach morphodynamic types and carried out beach morphodynamic classification within the beach morphodyamic framework (e.g., Qi et al., 2009; Huang et al., 2011; Zhou et al., 2013; Cheng et al., 2014; Liu et al., 2014; Li, 2015), however, these work directly utilized the $\Omega$ (and RTR) parameter to classify beaches, ignoring wave background of high or low energy beaches and the consideration that the parameter is essentially predictive. Therefore, the objectives of this paper are (1) to conduct beach morphodynamic classifications on straight (tangential) coastal sectors of 12 embayed sandy beaches based on the investigation of beach morphology, and wave, tide and sediment characteristics, and (2) to evaluate the applicability of the $\Omega$ and $R T R$ parameters along the west Guangdong coastline, which will elucidate the impact or control of the environmental factors such as waves, tides and sediment size on beach morphology.

\section{Study area and environmental setting}

The study area covers 12 headland-bay sandy beaches in Zhanjiang city, Maoming city and Yangjiang city along the coastline of the west Guangdong: Jizhao Bay, Wangcun Bay, Aonei Bay, Shuidong Bay, Shuidong Dong, Bohe Bay, Fuhu Bay, Hebei Bay, Hailing Bay, Shili Beach, Dongdao Beach and Sanya Bay (Figure 1). It is considered geotectonically as a part of South China fold system including Neocathaysian, EW and NS main structural systems, among which the Neocathaysian structural system plays a dominant role to ultimately constitute the basic framework of South China coastal configuration (Wang et al., 1991). The study area also experiences multiple regional tectonic movements, forming a series of well-developed folds and fractures (Cai et al., 2007). The main coastal bedrock is granite or granodiorite due to the Yanshan Stage magma intrusion in the Mesozoic, which is commonly found in the continental peninsulas, headlands and coastal islands. The combination of the geologic structure and lithological strata determines coastal framework and general trend, and influences shoreline configuration and sediment source and distribution, which are the intrinsic factors for coastal development. During the Holocene postglaciation period, the transgression caused the previous shoreline at the margin of the present continental shelf to advance onshore and reached the contemporary height (Ren, 1994), which also implied an import sediment source. The shorelines constantly undergo the wave action of long-term oblique swell, leaving a series of headland-bay beaches with different orientations and dimensions. The beaches are characterized by the indented configuration constrained and 
separated by rocky headlands, resulting from the interaction between the geological setting and hydrodynamic processes.

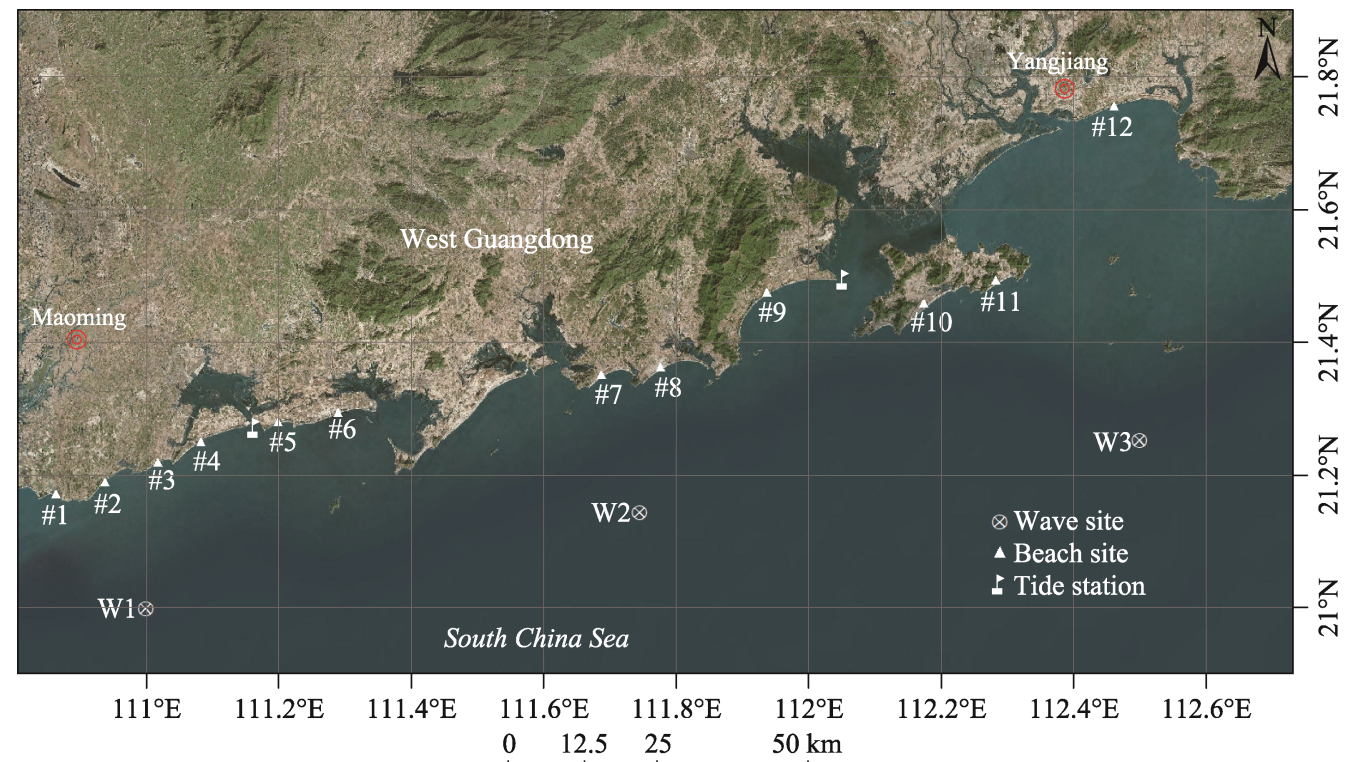

Figure 1 The study area showing 12 studied headland-bay beaches and wave and tide data sources in the west Guangdong. The beaches include \#1-Jizhao Bay $\left(21.392^{\circ}-21.392^{\circ} \mathrm{N}, 110.847^{\circ}-110.853^{\circ} \mathrm{E}\right)$, \#2-Wangcun Bay $\left(21.388^{\circ}-21.418^{\circ} \mathrm{N}, 110.891^{\circ}-110.929^{\circ} \mathrm{E}\right)$, \#3-Aonei Bay $\left(21.418^{\circ}-21.429^{\circ} \mathrm{N}, 110.958^{\circ}-110.982^{\circ} \mathrm{E}\right)$, \#4- Shuidong Bay $\left(21.429^{\circ}-21.459^{\circ} \mathrm{N}, 110.997^{\circ}-111.053^{\circ} \mathrm{E}\right)$, \#5-Shuidong Dong $\left(21.460^{\circ}-21.469^{\circ} \mathrm{N}, 111.102^{\circ}-\right.$ $\left.111.128^{\circ} \mathrm{E}\right)$, \#6-Bohe Bay $\left(21.464^{\circ}-21.481^{\circ} \mathrm{N}, 111.136^{\circ}-111.199^{\circ} \mathrm{E}\right)$, \#7-Fuhu Bay $\left(21.507^{\circ}-21.525^{\circ} \mathrm{N}\right.$, $\left.111.489^{\circ}-111.527^{\circ} \mathrm{E}\right)$, \#8-Hebei Bay $\left(21.512^{\circ}-21.534^{\circ} \mathrm{N}, 111.554^{\circ}-111.598^{\circ} \mathrm{E}\right)$, \#9-Hailing Bay $\left(21.593^{\circ}-\right.$ $\left.21.618^{\circ} \mathrm{N}, 111.690^{\circ}-111.751^{\circ} \mathrm{E}\right)$, \#10-Shili Beach $\left(21.579^{\circ}-21.604^{\circ} \mathrm{N}, 111.877^{\circ}-111.911^{\circ} \mathrm{E}\right)$, \#11-Dongdao Beach $\left(21.618^{\circ}-21.624^{\circ} \mathrm{N}, 111.982^{\circ}-111.996^{\circ} \mathrm{E}\right)$ and $\# 12$-Sanya Bay $\left(21.787^{\circ}-21.807^{\circ} \mathrm{N}, 112.087^{\circ}-112.12856^{\circ} \mathrm{E}\right)$.

The wind directions in the study area are largely dominated by the monsoon transition all year round due to the geographical location in the subtropical East-Asian monsoon climate region. The dominant seasonal wave directions are greatly consistent with the seasonal wind directions ( $\mathrm{Yu}, 1984)$. High and long deep-water waves occur during the prevailing NE monsoon in winter, while the summer SW monsoon produces relatively low and short waves. However, extremely high waves in a short period because of tropical cyclone activity during summer months occasionally occur, which exert a significant effect on variations in wave conditions and beach morphology (Qi et al., 2010). Limited measured wave data are available to reflect wave characteristics in the study area. For example, at Shuidong Bay, the mean wave height and period is $0.66 \mathrm{~m}$ and $4 \mathrm{~s}$, respectively, and the measured maximum wave height is $4.42 \mathrm{~m}$ corresponding to a typhoon event (Chen and $\mathrm{Li}, 1990$ ). However, the mean wave height is $0.20 \mathrm{~m}$ and the mean wave period is $2.2 \mathrm{~s}$ in a sheltered environment at Hailing Bay (CCRBC, 1999).

The irregular, semi-diurnal tides are characteristic of the west Guangdong coastline, which potentially have an indirect or passive effect on beach evolution. Previous studies indicated that a decreasing spatial trend of mean tide ranges from west to east in the study area (e.g., Fang, 1986; Cai et al., 2007). Shuidong Bay has a mean tidal range of $1.90 \mathrm{~m}$ with a mean spring tidal range of $2.29 \mathrm{~m}$ in the west of the study area (Chen and Li, 1990), while 
the mean tidal range is $1.57 \mathrm{~m}$ and the maximum tidal range $3.92 \mathrm{~m}$ at Hailing Bay in the east (CCRBC, 1999).

For the majority of the beaches in the present paper, few studies concerned beach morphodynamics, except Shuidong Bay with detailed studies. For instance, Chen (1990, 2000), Chen et al. (1991) and Chen and Li (1993) related beach morphology to wave parameters; Chen (1991) conducted a dynamic depositional environment study; and Chen (1995) explored the beach response to one typhoon event in the Shuidong Bay.

\section{Data collecting and method}

\subsection{Dataset}

Twelve embayed beaches were selected to conduct a beach morphodynamic investigation along the coastline of the west Guangdong in July and August, 2017. The beaches are bounded by rocky headlands with variable shoreline lengths $(1.5-15 \mathrm{~km})$. The total of 53 profiles were arranged on the relatively straight segment (or termed as tangential segment) for each beach, including Jizhao Bay (4), Wangcun Bay (6), Aonei Bay (3), Shuidong Bay (8), Shuidong Dong (5), Bohe Bay (4), Fuhu Bay (3), Hebei Bay (3), Hailing Bay (5), Shili Beach (4), Dongdao Beach (4), and Sanya Bay (4). Along each profile, a RTK-GPS was used to survey the cross-shore beach morphology with a vertical precision of $\pm 15 \mathrm{~mm}$ from a backshore fixed benchmark to the low-water line, and two surficial sand samples were collected on the upper and lower intertidal profile, respectively. Beach morphodynamic types were visually identified on the basis of the profile form (concave, convex or linear) and characteristic features (berm, cusp, rip, bar, etc.), supplemented with breaker types and aerial images. The sand samples were measured with a MasterSize 2000 Laser Particle Analyzer to obtain the median and the volume percentage of each sand fraction. The values of mean sand size were calculated by the graphical method proposed by Folk and Ward (1957).

Because of the trend of increasing tide range from east to west in the area (Fang, 1986; Cai et al., 2007), the tide data from Shuidong and Zhapo tide gauge stations used to conduct a tidal harmonic analysis to obtain the mean spring tidal range (MSR). A linear interpolation technique based on the geographical location was implemented to allocate a unique $M S R$ for each beach. Due to lacks of regional scale wave data available, the ERA-Interim wave data in 1979-2017 were used with a $6 \mathrm{~h}$ temporal and $0.125^{\circ}$ spatial resolution at three wave model nodes: $\mathrm{W} 1\left(111^{\circ} \mathrm{E}, 21^{\circ} \mathrm{N}\right), \mathrm{W} 2\left(111.75^{\circ} \mathrm{E}, 21.125^{\circ} \mathrm{N}\right)$ and $\mathrm{W} 3\left(112.5^{\circ} \mathrm{E}, 21.25^{\circ} \mathrm{N}\right)$. Wan et al. (2015) conducted an experimental verification between the ERA-Interim reanalysis wave data and the measured wave data from the deep-water buoy in the South China Sea, showing a high precision in the deep-water wave field. It has long been known that the deep-water wave climate is the primary source of temporal variation in beach morphodynamic state (Short and Wright, 1981). However, the deep-water wave power will be attenuated and redistributed at the breakpoint, depending on the shelf, nearshore and coastal morphology. Thus, the deep-water wave power will determine the potential mode and range of beach morphodynamic states while breaker wave power actually governs the actual mode and range for a given beach. Based on this, the ERA-Interim wave data is helpful to understand background wave environments and associated spatial variation in wave characteristics in the study area, particularly in the case of extreme lack of measured wave data. The pre- 
processing results show that there exists a decreasing trend of offshore wave heights and periods from east to west in the west Guangdong. Similarly, the linear interpolation technique was conducted to attain a unique mean wave height and a period for each beach.

\subsection{Method}

This paper used the dimensionless fall velocity parameter $(\Omega)$ and the relative tide range parameter $(R T R)$ within the beach morphodynamic framework to compare the actual beach types with the predicted beach types. The $\Omega$ indicates whether reflective, intermediate or dissipative beach and surf zone conditions will prevail, and the $R T R$ reflects the relative importance of swash, surf zone and shoaling wave processes in determining beach morphology. Currently there are no unified criteria to determine the use of the mean wave height and period (Anthony, 1998), however, many existing studies normally utilized a combination of the offshore significant wave height $\left(H_{s}\right)$ and peak wave period $\left(T_{p}\right)$. Additionally, the acquisition of the breaker height through transferring offshore waves to inshore waves is another problem. For example, Scott et al. (2011) used a numerical model to obtain the breaker wave height, which led to a reduction in offshore wave height. However, Jackson et al. (2005) used a simple shoaling relationship presented by Komar and Gaughan (1972) to characterize breaker wave heights, resulting in an increase in offshore wave height. This empirical relationship is site-specific and has been widely applied in Chinese coastal studies (e.g., Li, 2015; Yu et al., 2016); however, it needs to be verified its applicability. Thus, the paper directly used a mean offshore significant wave height $\left(H_{s}\right)$, rather than breaker height, and by convention, a peak wave period $\left(T_{p}\right)$ was obtained by an empirical relationship of $T_{p}=1.41 T_{z}$ in China (in which $T_{z}$ is mean wave height) proposed by (Hua et al., 2004).

$$
\begin{gathered}
\Omega=H_{s} / W_{s} T_{p} \\
R T R=M S R / H_{s}
\end{gathered}
$$

where $M S R$ is the mean spring tide range (m) and $W_{s}$ is the sediment fall velocity $(\mathrm{m} / \mathrm{s})$, which can be derived through an empirical relationship suggested by Ferguson and Church (2004).

$$
W_{s}=\frac{\operatorname{Rg} D_{50}^{2}}{C_{1} v+\left(0.75 C_{2} \operatorname{Rg} D_{50}^{2}\right) 0.5}
$$

where $R$ is submerged specific gravity (1.65 for quartz in water), $g$ is gravity unit $(9.8 \mathrm{~N} / \mathrm{kg}$ ), $D_{50}$ is median sand size, $v$ is kinematic viscosity of the fluid $\left(10^{-6} \mathrm{~kg} \mathrm{~m}^{-1} \mathrm{~s}^{-1}\right.$ for water at $20^{\circ} \mathrm{C}$ ), and $C_{1}$ and $C_{2}$ are constants with $C_{1}=18$ and $C_{2}=1$.

To characterize wave conditions of the offshore wave energy level, $P_{0}$ is calculated for each beach, which is given by

$$
P_{0}=\rho g H_{s}^{2} C_{g} / 16
$$

where $\rho$ is seawater density, $g$ is gravity, $H_{s}$ is offshore significant wave height and $C_{g}$ is wave group velocity.

\section{Results}

\subsection{Wave characteristics}

The statistics of annual mean significant wave heights and periods at W1, W2 and W3 show 
that the average wave height and period during 1979-2017 is $1.04 \mathrm{~m}$ and $5.9 \mathrm{~s}$ at $\mathrm{W} 1,1.10$ $\mathrm{m}$ and $6.0 \mathrm{~s}$ at $\mathrm{W} 2,1.23 \mathrm{~m}$ and $6.3 \mathrm{~s}$ at $\mathrm{W} 3$, respectively. There exists a spatial decreasing variation from east to west for the average wave heights and periods in west Guangdong. Figure 2 indicates that the annual variation of wave height and period is significant with the minimum average wave height and period in 1979-2017 being $0.39 \mathrm{~m}$ and $4.1 \mathrm{~s}$, and the maximum average wave height and period reaching $4.38 \mathrm{~m}$ and $10.4 \mathrm{~s}$, respectively. The 39-year time series of annual mean significant wave heights and periods, and maximum and minimum wave heights and periods show that the annual mean and minimum wave heights and periods have an insignificant temporal variability in comparison with maximum wave heights and periods. The remarkable variation in annual maximum wave heights and periods largely reflects the impact of occasional occurring typhoon events on wave conditions.

Wave direction at W3 in Figure 3 mainly varies in the first and second quadrants, largely corresponding to the monsoon transition. Waves firstly turn clockwise from NEE in December to $\mathrm{S}$ in summer months and then reverse to NEE in November. The monthly variation in wave heights and periods as shown in Figure 4 indicates wave conditions have the characteristics of seasonal variability. Maximum monthly-averaged wave height $(1.70 \mathrm{~m})$ and period $(6.8 \mathrm{~s})$ prevail in December when the winter monsoon is most fierce, while minimum monthly-averaged wave height $(0.90 \mathrm{~m})$ and period $(5.8 \mathrm{~s})$ occur in May when the monsoon direction begins to shift and the summer monsoon prevails. It seems that beach morphology may change in the form of yearly cyclic (winter bar profile-summer berm profile) in response of the seasonal varying wave conditions. Considering the winter prevailing direction in relation to the studied coastline orientation, although waves in winter months are more energetic than in summer and are expected to exert greater impact on the beach morphology, the energetic winter offshore waves are actually offshore-directed, and the inshore waves are more likely to be relatively low, which potentially play a limited impact on beach morphology.
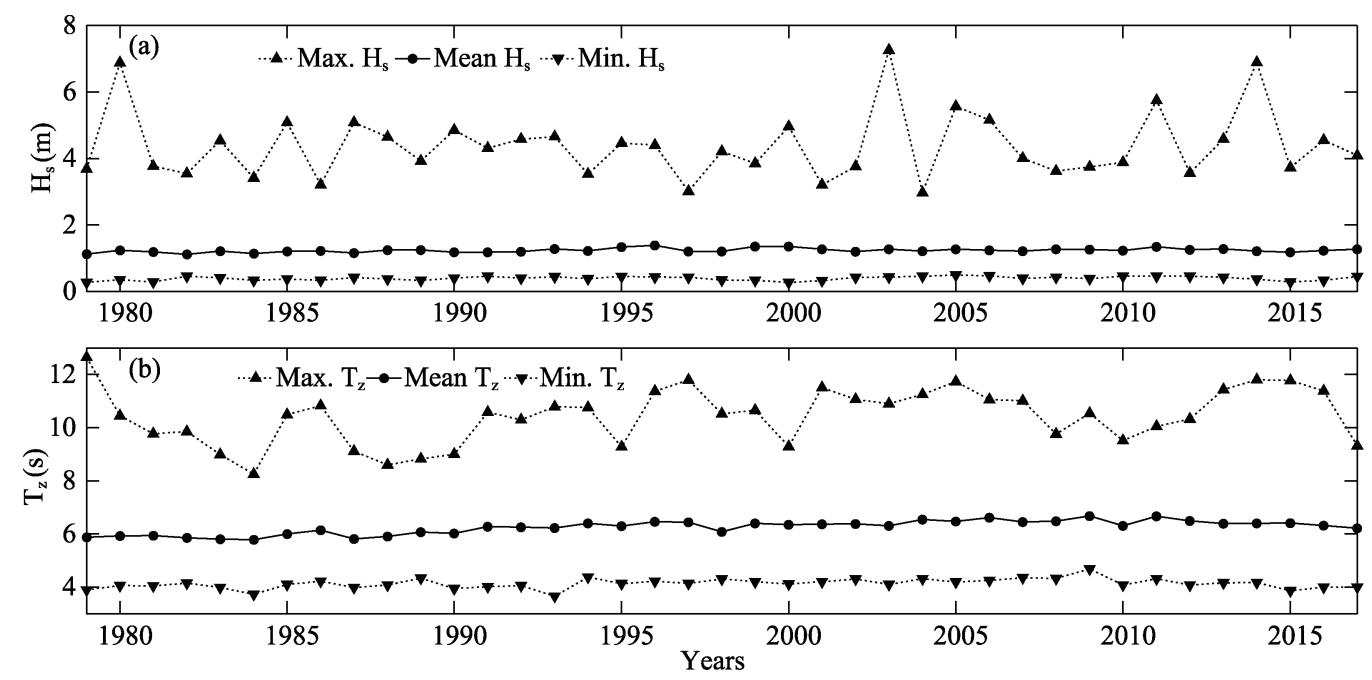

Figure 2 The variations of (a) annual mean significant wave height (Mean $\left.\mathrm{H}_{\mathrm{s}}\right)$, maximum wave height $\left(\mathrm{Max}\right.$. $\left.\mathrm{H}_{\mathrm{s}}\right)$ and minimum wave height $\left(\mathrm{Min} . \mathrm{H}_{\mathrm{s}}\right)$, and (b) annual mean significant wave period (Mean $\mathrm{T}_{\mathrm{z}}$ ), maximum wave period (Max. $\mathrm{T}_{\mathrm{z}}$ ), and minimum wave period (Min. $\mathrm{T}_{\mathrm{z}}$ ) during 1979-2017 at W3 

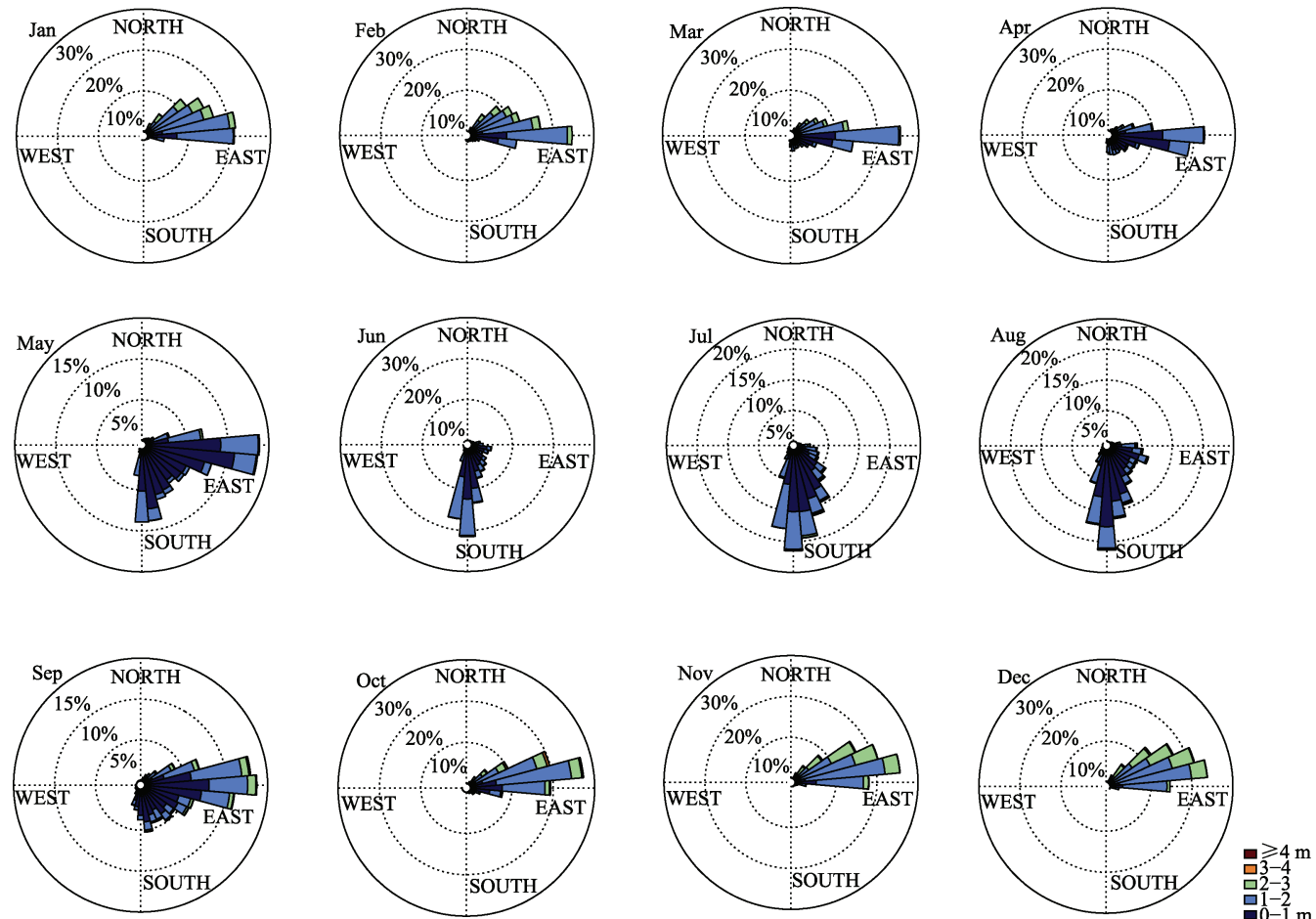

Figure 3 The wave rose showing the characteristics of the monthly wave directions at W3
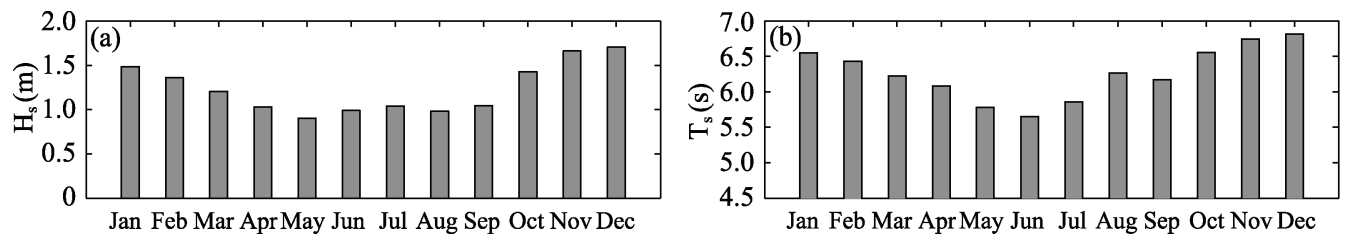

Figure 4 The variation of (a) monthly mean significant wave heights and (b) wave periods at W3 during 19792017

\subsection{Sediment characteristics}

Figure 5 shows most beaches consist of medium or fine fraction. Three beaches (Wangcun Bay, Shuidong Dong, and Hailing Bay) are composed of fine sand, other three beaches (Shuidong Bay, Hebei Bay and Shili Beach) consist of medium sand, and Dongdao Beach is composed of coarse fine. The beaches, including Jizhao Bay, Bohe Bay and Sanya Bay, are characterized by a medium-grained upper intertidal profile and a fine-grained lower intertidal profile. While Aonei Bay consists of medium sand (1.26 $\Phi)$ on the upper intertidal profile with coarse sand $(0.59 \Phi)$ on the lower intertidal profile, Fuhu Bay is composed of coarse sand $(0.96 \Phi)$ and medium sand $(1.21 \Phi)$ on the upper and lower intertidal profile, respectively. 
(a) Upper intertidal zone



(b) Lower intertidal zone

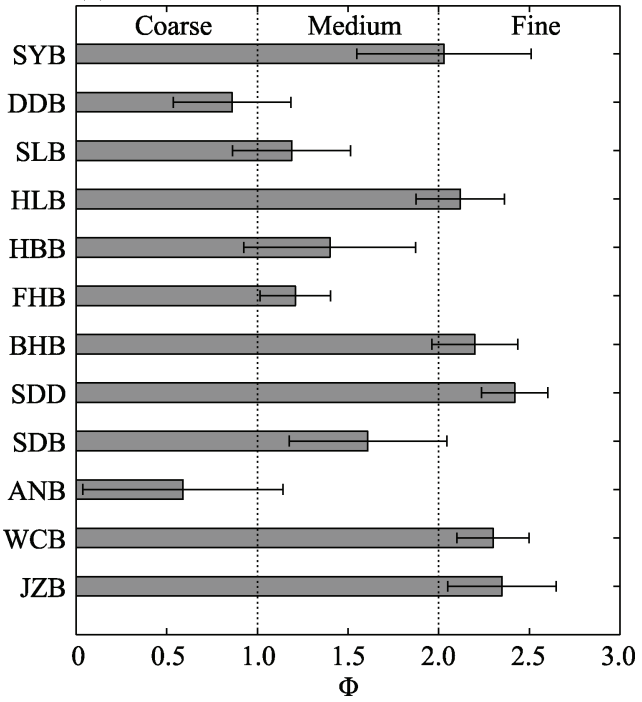

Figure 5 Mean sand size and standard deviation of (a) upper intertidal profile and (b) lower intertidal profile for 12 west Guangdong beaches

\subsection{Actual beach morphodynamic types}

The actual beach morphodynamic types for 12 studied beaches during the survey were grouped into three categories based on field profile measurement, wave, tide and sediment characteristics, the occurrence of typical beach morphologies, dominant process and aerial images (Table 1).

Table 1 Actual beach morphodynamic type diagnoses based on sediment characteristics, intertidal gradient, breaker type, characteristic morphology and dominant process

\begin{tabular}{|c|c|c|c|}
\hline & Reflective & Intermediate & Non-barred dissipative \\
\hline Beach sites & Dongdao Beach & $\begin{array}{l}\text { Bohe Bay, Fuhu Bay, Hebei Bay, } \\
\text { Shili Beach, Sanya Bay }\end{array}$ & $\begin{array}{l}\text { Jizhao Bay, Wangcun Bay, Aonei } \\
\text { Bay, Shuidong Bay, Shuidong Dong, } \\
\text { Hailing Bay }\end{array}$ \\
\hline Sand characteristics & Coarse sand & Mainly medium sand & Fine sand \\
\hline Intertidal gradient & Steep $\left(>10^{\circ}\right)$ & $\begin{array}{l}\text { Steeper on the upper beach } \\
\left(6^{\circ}-10^{\circ}\right) \text { and moderately steep on } \\
\text { the lower beach }\left(3^{\circ}-6^{\circ}\right)\end{array}$ & $\begin{array}{l}\text { Moderately steep on the upper beach } \\
\left(3^{\circ}-5^{\circ}\right) \text { and flat on the lower beach } \\
\left(1^{\circ}-2^{\circ}\right)\end{array}$ \\
\hline Breaker types & $\begin{array}{l}\text { Plunging } \\
\text { breakers }\end{array}$ & Plunging breakers & $\begin{array}{l}\text { Plunging breakers during high tide, } \\
\text { spilling breakers during low tide }\end{array}$ \\
\hline $\begin{array}{l}\text { Characteristic } \\
\text { morphology }\end{array}$ & $\begin{array}{l}\text { Swash cusps } \\
\text { and berm }\end{array}$ & Rip/bar morphology & $\begin{array}{l}\text { Concave profile, featureless } \\
\text { morphology }\end{array}$ \\
\hline Dominant process & $\begin{array}{l}\text { Swash } \\
\text { zone/surf zone }\end{array}$ & Surf zone & Surf zone/shoaling \\
\hline
\end{tabular}

\subsubsection{Reflective beach}

Dongdao Beach is characterized by a steep $\left(11.1^{\circ}\right)$ and narrow intertidal profile, coarse-grained sand, well-developed beach berm, and regular swash cusp morphology with cusp spacing at $\sim 8 \mathrm{~m}$. The annual mean wave height is about $0.96 \mathrm{~m}$ and the mean spring tidal range is $1.79 \mathrm{~m}$, showing the beach in a wave-dominated, micro-tidal environment. 
Waves begin to break near the shore in the pattern of plunging breakers and then surge up to the beach face. All are indicative of the reflective type (Figure 6; e.g. Wright and Short, 1984; Masselink and Short, 1993; Scott et al., 2011).

\subsubsection{Intermediate beaches}

Five beaches, such as Bohe Bay, Fuhu Bay, Hebei Bay, Shili Beach and Sanya Bay, are considered to be intermediate. Their intertidal profiles mainly consist of medium sand, and the upper intertidal beaches are relatively steep $\left(6.2^{\circ}-9.8^{\circ}\right)$ with a moderate-gradient $\left(3.0^{\circ}-6.0^{\circ}\right)$ surf zone. Beach berms normally develop, and occasionally, swash cusps occur on the upper intertidal zone. The annual mean wave height is $0.88-0.98 \mathrm{~m}$ and the mean spring tidal range is less than $2 \mathrm{~m}$. Plunging breakers prevail in the surf zone. The presence of rip morphology as shown in Figure 6 is the most important indicator for the intermediate beach type (e.g., Wright and Short, 1984; Masselink and Short, 1993; Sénéchal et al., 2009).

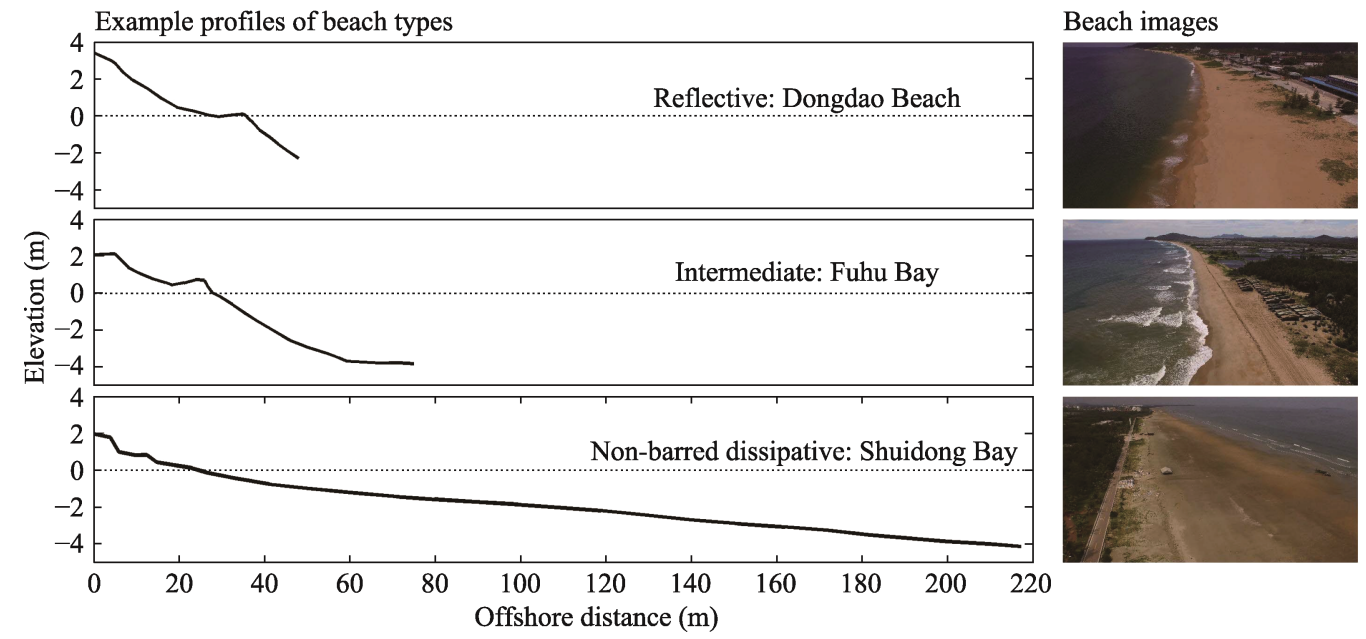

Figure 6 Examples of reflective, intermediate, and dissipative beach types with cross-shore profiles (left) and aerial photographic images (right)

\subsubsection{Dissipative beaches}

Six beaches including Jizhao Bay, Wangcun Bay, Aonei Bay, Shuidong Bay, Shuidong Dong and Hailing Bay are classified as non-barred dissipative type. Apart from Aonei Bay that consists of relative coarse sand, the rest of the beaches are largely composed of relative fine sand. Generally, no beach berm or cusp occurs. The annual mean wave height is less than $0.9 \mathrm{~m}$ and the mean spring tide range is more than $2 \mathrm{~m}$, indicating these beaches in a wave-dominated, tide-modified environment. The upper intertidal gradients are moderate $\left(3.4^{\circ}-5.2^{\circ}\right)$, however, the lower intertidal profiles are flat $\left(1.2^{\circ}-2.1^{\circ}\right)$ due to fine-grained sand composition. During high tides, plunging breakers prevail; however, during low tides, waves break in the form of spilling type. The wide, concave, featureless profiles are characteristic of the non-barred dissipative type. This beach type is unusual in a micro-tidal environment expect in sheltered, micro-tidal, low wave-energy environments with fine sand (Klein et al., 2010; Aleman et al., 2015). However, the non-barred dissipative beaches are mainly in meso- and macro-tidal environments (e.g., Short, 2006; Scott et al., 2011). 


\subsection{Applicability of $\Omega$ and RTR parameters}

Given the fact of the offshore-directed waves in winter months in Section 4.1, the mean wave height and period from March to September were chosen to represent the modal wave conditions. Based on the unique values of mean wave height and period, MSR and upper intertidal sand size, $\Omega$ and $R T R$ parameters were calculated and allocated to each of the beaches as shown in Figure 7. All beaches but two fall into the "barred" type in the intermediate group if a $\Omega$ critical threshold is set at 1.5. Masselink and Pattiaratchi (2001) conducted field experiments on the sheltered coast of Perth in Western Australia, and suggested that $\Omega=1.5$ can make a distinction between non-barred beaches $(\Omega<1.5)$ and barred beaches $(\Omega>1.5)$ based on a daily, weekly or seasonal time-scale. The actual reflective and intermediate "barred" types can be better predicted based on $\Omega$ and $R T R$, however, the model of Masselink and Short (1993) has a poor predictive capacity for the non-barred dissipative beaches.

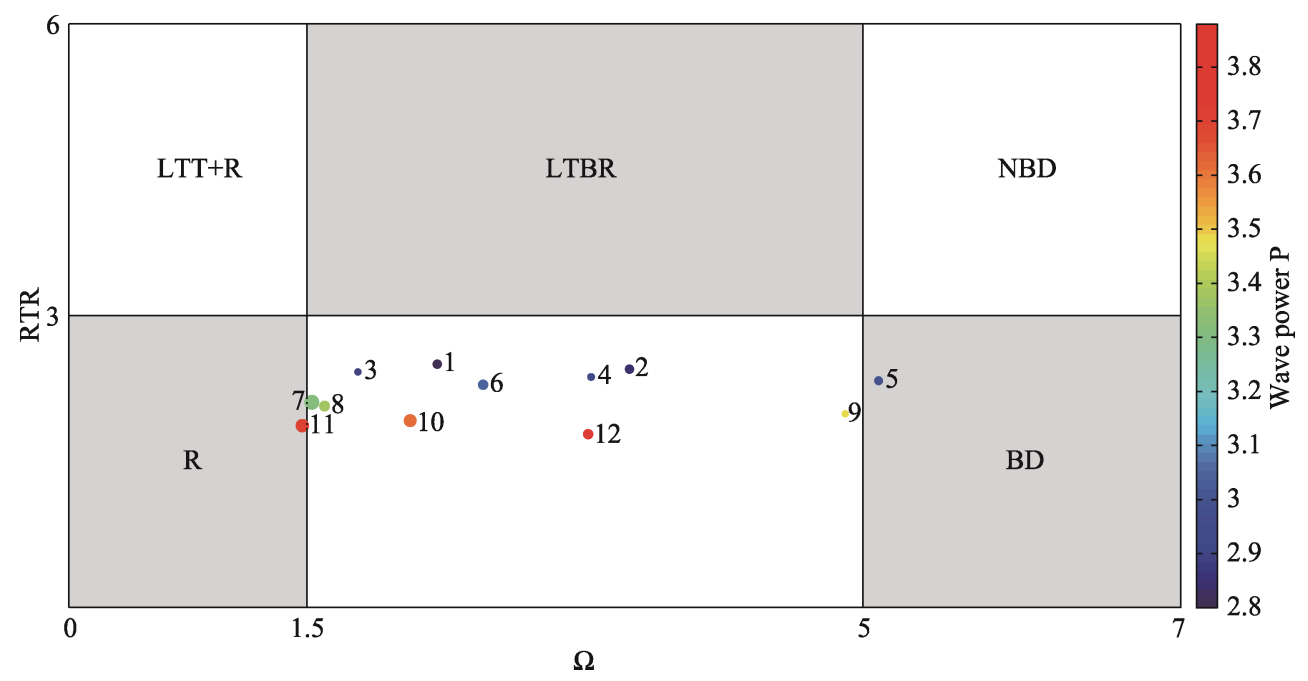

Figure 7 Prediction of beach morphodynamic types (R: reflective; B: barred; BD: barred dissipative; LTT $+\mathrm{R}$ : low tide terrace with rip; LTBR: low tide bar or rip; NBD: non-barred dissipative) within the beach morphodynamic framework based on the dimensionless fall velocity parameter $(\Omega)$ and relatively tidal range parameter (RTR). The marker sizes represent the relative gradients of the upper intertidal profiles and the right color bar reflects the absolute wave energy level for 12 studied beaches (1: Jizhao Bay; 2: Wangcun Bay; 3: Aonei Bay; 4 : Shuidong Bay; 5: Shuidong Dong; 6: Bohe Bay; 7: Fuhu Bay; 8: Hebei Bay; 9: Hailing Bay; 10: Shili Beach; 11: Dongdao Beach; 12: Sanya Bay).

\section{Discussions}

\subsection{Application conditions of the use of $\Omega$ and $R T R$ parameters}

The $\Omega$ parameter can be used to predict and identify beach morphodynamic types, which has been receiving increasing attention (e.g., Wright and Short, 1984; Masselink and Short, 1993; Klein and Menezes, 2001; Costas et al., 2005; Gómez-Pujol et al., 2007; Scott et al., 2011; Loureiro et al., 2013; Aleman et al., 2015; Veas et al., 2017). This parameter was originally proposed for the high-energy, micro-tidal, exposed beaches on New South Wales. Beach 
morphology can change in response of rising or falling waves in spite of the response lag of beach morphology, implying that beach morphology is in agreement with prevailing wave conditions. However, for low-energy beaches, though a reflective value of $\Omega$ may be attained because of low modal (most frequent) waves occurring over a prolonged period of time, beaches are in fact in a highly dissipative state (Short, 1975; Anthony, 1998). The beach morphology in low-energy environments is largely inherited from high-energy events (storms), indicating a disequilibrium with the prevailing wave conditions. Thus, the use of $\Omega$ and RTR parameters to conduct beach morphodynamic classification within the morphodynamic framework must preferentially consider wave-energy conditions for the beach, i.e., beach morphology responsiveness. In this paper, the studied beaches are in relatively low-energy environments (mean wave height $<1 \mathrm{~m}$ from March to September). Masselink and Short (1993) emphasized the role of absolute wave energy level for the low-energy conditions. Scott et al. (2011) tentatively suggested that a wave energy level threshold has to be more than $3 \mathrm{KWm}^{-1}$ in order to produce three-dimensional bar/rip morphology. However, for the Barceloneta beach in low-energy environment, Jiménez et al. (2008) proposed the mean wave conditions can not characterize beach morphodynamic changes, and high-energy events with the wave energy level more than $3 \mathrm{KWm}^{-1}$ drive beach morphological changes. The results in Section 4.4 show that $\Omega$ has a good predictive capacity for the micro-tidal $(M S R<2 \mathrm{~m})$ environments with wave energy level $>3 \mathrm{KWm}^{-1}$, but poor for the environments with $M S R>2 \mathrm{~m}$ and wave energy level $<3 \mathrm{KWm}^{-1}$. Thus, an absolute wave energy level threshold of $3 \mathrm{KWm}^{-1}$, as shown in Figure 7, may distinguish higher or lower energy beaches in the context of relatively low energy environments in west Guangdong.

The prediction of $\Omega$ and $R T R$ parameters has failed for six non-barred dissipative beaches. Except for Hailing Bay, five beaches are characterized by lower wave heights with $M S R>2$ $\mathrm{m}$. Although at Hailing Bay the mean offshore wave height is relatively high $(0.93 \mathrm{~m})$, the beach is actually in a sheltered environment (cf. Figure 1) and the actual inshore wave heights were overestimated (CCRBC, 1999), which, in turn, may lead to underestimation of tide effect. Provided that the beach can respond fully to the variation in wave conditions, the low waves will cause beaches more skewed toward reflective extreme. But the actual beaches are in a non-barred dissipative state, showing that beach morphology misfits the mean wave conditions and largely respond to the previous storm event. Masselink and Short (1993) pointed out that increasing tide range leads to the reduction for the overall beach gradient and inhibits the formation of offshore bar. Therefore, tides play an increasing role in beach morphology evolution, resulting in the non-barred dissipative type.

\subsection{Potential impact of the seasonal variation in wave conditions on beach cycle}

It has long been known that the model of "winter bar profile-summer berm profile" can characterize an annual cyclic variation in beach morphology in the environments with high storm waves in winter and low swell in summer. Here, wave conditions in the study area have distinct seasonal variability due to higher winter wave heights and lower summer wave heights without considering the potential, extremely high typhoon waves. Thus, some studies (e.g., Li et al., 2002; Peng et al., 2005) took it for granted that the beaches in South China were expected to complete a full sweep from the winter bar profile to the summer berm 
berm profile in response to the seasonal variation in wave heights. However, in fact, the more energetic waves in winter are offshore-directed as shown in Section 4.1, which will potentially play limited impact on beach morphologies. This phenomenon will narrow the range of wave height variation without considering the effect of typhoon waves, and therefore the range of beach morphological change. For example, Cai et al. (2005) conducted a seasonal beach morphological study on eight beaches in South China and showed a non-significant difference between winter and summer profiles for most of the beaches. The beaches were more likely to be in one beach morphodynamic type. The model of "winter bar profile-summer berm profile" is applicable only in Northern Hemisphere west coast swell and mid-latitude protected sea coasts, and is not applicable for the high-energy, southeastern Australian coasts (Short, 1978). In this paper, we also suggest that the model is not applicable for the studied beaches in monsoon environments. Because of the fact that two or three typhoons assault the study area every year (Qi et al., 2010), it appears that the model of "storm-post-storm profile" with the temporal scale less than the seasonal scale is more appropriate along the coastline in South China. The typhoon events would potentially drive and control beach morphodynamic type to vary significantly (e.g., from reflective to dissipative type), depending on typhoon intensity and duration. However, under calm conditions following typhoon events, the relatively low annual mean wave heights with the narrowed range are more likely to cause the beach in one or several beach morphodynamic types, rather than a complete beach cycle from the reflective state (the summer berm profile) to the dissipative stage (the winter bar profile). However, the beaches might complete morphological variation from the dissipative type under the typhoon environments to a certain beach type over a long period under calm condition following the typhoon events, which needs future studies on beach type response to typhoon events and actual breaker wave conditions. Particularly for the non-barred dissipative types, the beach morphologies are much more likely to respond the typhoon events.

\section{Conclusions}

This paper chooses 12 straight beaches on the embayed coasts in the west Guangdong under the subtropical monsoon climate to conduct beach morphodynamic classification and to assess the applicability of the widely used $\Omega$ and $R T R$ parameters in the study area. Main conclusions are as follows.

(1) One reflective, five intermediate, and six non-barred dissipative beaches are identified based on morphological, sedimentological and hydrodynamic characteristics. The reflective beach is steep and consists of coarse sand with typical berm and cusp morphologies. The intermediate beaches are relatively steep and composed of medium sand, characterized by the occurrence of rip morphology. The non-barred dissipative beaches largely consist of relatively fine sand with a flat lower intertidal profile. Sand size appears to be a key indicator to make a distinction among different beach types.

(2) The studied beaches are in relatively low-energy environments with offshore mean $H_{s}$ $<1 \mathrm{~m}$. The combination of $\Omega$ and $R T R$ parameters predicts well for the reflective and intermediate types, characterized by the absolute wave energy level more than $3 \mathrm{KWm}^{-1}$ and MSR less than $2 \mathrm{~m}$. However, the model is not applicable for the non-barred dissipative 
beaches in the marine environments with wave energy level less than $3 \mathrm{KWm}^{-1}$ and $M S R$ more than $2 \mathrm{~m}$. The results also imply that the model is not necessarily suitable for the other coasts where low-energy beach environments prevail as some previous studies have shown.

(3) Beach morphologies do not necessarily to complete a traditional seasonal beach cycle from the summer berm profile to the winter bar profile in spite of seasonal variability of wave characteristics. The breaker wave conditions from deep-water wave field and beach type response to typhoon events are required to further research for accurately depicting the real range of wave variations and thus the variations of beach types within the modern beach morphodynamic framework.

\section{Acknowledgement}

The authors thank Professor Gerd Masselink in the University of Plymouth of UK for providing ECMWF's ERA-Interim reanalysis wave data, and comprehensive guidance and inspiration on beach morphodynamics, and also thank Jiang Guoyi, Gao Yan, Yuan Cheng, Jiang Bin and Liu Canhui in School of Surveying and Land Information Engineering, Henan Polytechnic University for their help on the field investigation.

\section{References}

Aleman N, Robin N, Certain R et al., 2015. Longshore variability of beach states and bar types in a microtidal, storm-influenced, low-energy environment. Geomorphology, 241: 175-191.

Anthony E, 1998. Sediment-wave parametric characterization of beaches. Journal of Coastal Research, 14(1): 347-352.

Cai Feng, Cao Huimei, Su Xianze et al., 2007. Analysis on morphodynamics of sandy beaches in South China. Journal of Coastal Research, 23(1): 236-246.

Cai Feng, Su Xianze, Cao Huimei et al., 2005. Analysis on morphodynamics of sandy beaches in South China. Acta Oceanologica Sinica, 27(2): 106-114. (in Chinese)

Chen Zishen, 1991. Application of correspondence analysis to discriminate dynamic depositional environments in Shuidong Bay, western Guangdong Province. Tropic Oceanology, 10(1): 55-62. (in Chinese)

Chen Zishen, 1995. The response characteristics of beaches in an arc-shaped coast to the typhoon with high waves. China Science Bulletin, 40(23): 2168-2170. (in Chinese)

Chen Zishen, 2000. Analysis on spatial and temporal processes of beach profile variations. Marine Science Bulletin, 29(2): 42-48. (in Chinese)

Chen Zishen, Li Chunchu, 1990. Analysis on geomorphological dynamics of beach profile of intermediate transitional zone in arc-shaped shore. Marine Sciences, 2(2): 6-12. (in Chinese)

Chen Zishen, Li Chunchu, 1993. Geomorphological states of beach profiles in an arc-shaped shore of Shuidong, western Guangdong. Tropic Oceanology, 12(2): 61-68. (in Chinese)

Chen Zishen, Li Chunchu, Luo Zhangren, 1991. Analysis on beach profile processes of tangential zone in arc-shaped shore of Shuidong Bay in Guangdong. Acta Oceanologica Sinica, 13(1), 82-90. (in Chinese)

Compilation Committee of "Records of Bays in China" (CCRBC), 1999. Bays in West Guangdong. Records of Bays in China, vol. 10. Beijing: China Ocean Press, 97-101. (in Chinese)

Costas S, Alejo I, Vila-Concejo A et al., 2005. Persistence of storm-induced morphology on a modal low-energy beach: A case study from NW-Iberian Peninsula. Marine Geology, 224 (1-4): 43-56.

Defeo O, McLachlan A, 2005. Patterns, processes and regulatory mechanisms in sandy beach macrofauna: A multi-scale analysis. Marine Ecology Progress Series, 295: 1-20.

Defeo O, McLachlan A, 2011. Coupling between macrofauna community structure and beach type: A deconstruc- 
tive meta-analysis. Marine Ecology Progress Series, 433: 29-41.

Dubois R N, 1988. Seasonal changes in beach topography and beach volume in Delaware. Marine Geology, 81: 79-96.

Fang Guohong, 1986. Tide and tidal current charts for the marginal seas adjacent to China. Chinese Journal of Oceanology and Limnology, 4(1): 1-16.

Ferguson R I, Church M, 2004. A simple universal equation for grain settling velocity. Journal of Sedimentary Research, 74: 933-937.

Folk R L, Ward W C, 1957. Brazos river bar: A study in the significance of grain size parameters. Journal of Sedimentary Petrology, 27(1): 3-26.

Gómez-Pujol L, Orfila A, Cañellas B et al., 2007. Morphodynamic classification of sandy beaches in low energetic marine environment. Marine Geology, 242 (4): 235-246.

Hua Feng, Fan Bin, Lu Yan et al., 2004. An empirical relationship between sea wave spectrum peak period and zero-crossing period. Advances in Marine Science, 22(1): 16-20. (in Chinese)

Hughes M G, Aagaard T, Baldock T E et al., 2014. Spectral signatures for swash on reflective, intermediate and dissipative beaches. Marine Geology, 355: 88-97.

Hughes M G, Masselink G, Brander R W, 1997. Flow velocity and sediment transport in the swash zone of a steep beach. Marine Geology, 138: 91-103.

Jackson D W T, Cooper J A G, Del Rio L, 2005. Geological control of beach morphodynamic state. Marine Geol$o g y, 216:$ 297-314.

Jiménez J A, Guillén J, Falqués A, 2008. Comment on the article "morphodynamic classification of sandy beaches in low energetic marine environment”. Marine Geology, 255 (1/2): 96-101.

Klein A H F, Ferreira Ó, Dias J M A et al., 2010. Morphodynamics of structurally controlled headland-bay beaches in southeastern Brazil: A review. Coastal Engineering, 57: 98-111.

Klein A H F, Menezes J T, 2001. Beach morphodynamics and profile sequence for a headland bay coast. Journal of Coastal Research, 17(4): 812-835.

Komar P D, Gaughan M K, 1972. Airy wave theory and breaker height prediction. Proceedings of 13th Coastal Engineering Conference, ASCE: 405-418.

Li Bogen, Xie Qinchun, Xia Xiaoming et al., 2002. Assessment on the adjustable fluctuation between erosion and deposition on beach profile in sandy arc-shaped shore. Donghai Marine Science, 20(1): 20-27. (in Chinese)

Li Zhiqiang, Zhu Yamin, 2015. Morphodynamic characteristics and classification of headland beaches in South China Coast. Marine Science Bulletin, 34(2): 181-189. (in Chinese)

Loureiro C, Ferreira Ó, Cooper J A G, 2013. Applicability of parametric beach morphodynamic state classification on embayed beaches. Marine Geology, 346: 153-164.

Masselink G, Pattiaratchi C B, 2001. Seasonal changes in beach morphology along the sheltered coastline of Perth, Western Australia. Marine Geology, 172: 243-263.

Masselink G, Short A D, 1993. The effect of tide range on beach morphodynamics and morphology: A conceptual beach model. Journal of Coastal Research, 9(3): 785-800.

Peng Jun, Cai Feng, Zhao Guangtao et al., 2005. The seasonal profile change characteristics due to beach reshaping southwest of Meizhou Island in Fujian. Transactions of Oceanology and Limnology, (4): 61-68. (in Chinese)

Qi Hongshuai, Cai Feng, Lei Gang et al., 2010. The response of three main beach types to tropical storms in South China. Marine Geology, 275: 244-254.

Ren Mei'e, 1994. Effects of sea level rise on deltaic regions in China and its countermeasures. In: Department of Geosicence, Chinese Academy of Science (ed.), Tendency of Sea Level Rise in Changjiang and Zhujiang River Deltas and Prediction on Sea Level Rise in 2050 A.D. Beijing: Science Press: 18-28. (in Chinese)

Scott T, 2009. Beach morphodynamics and associated hazards in the UK [D]. Plymouth: University of Plymouth.

Scott T, Masselink G, Russell R, 2011. Morphodynamic characteristics and classification of beaches in England and Wales. Marine Geology, 286: 1-20.

Sénéchal N, Gouriou T, Castelle B et al., 2009. Morphodynamic response of a meso- to macro-tidal intermediate 
beach based on a long-term data-set. Geomorphology, 107: 263-274.

Shepard F P, LaFonda E C, 1940. Sand movement along the Scripps Institution Pier. American Journal of Science, 238: $272-284$.

Short A D, 1975. Multiple offshore bars and standing waves. Journal of Geophysical Research, 80(27): 3838-3840.

Short A D, 1978. Wave power and beach-stages: A global model. Proceedings of 16 th coastal Engineering Conference, ASCE: 1145-1162.

Short A D, 1979. Three dimensional beach-stage model. The Journal of Geology, 87(5): 553-571.

Short A D, 2006. Australian beach systems: Nature and distribution. Journal of Coastal Research, 22 (1): 11-27.

Short A D, Aagaard T, 1993. Single and multi-bar beach change models. Journal of Coastal Research, SI(15): $141-157$.

Short A D, Hesp P A, 1982. Wave, beach and dune interactions in southeastern Australia. Marine Geology, 48: 259-284.

Short A D, Hogan C, 1994. Rip currents and beach hazards: their impacts on public safety and implications for coastal management. Journal of Coastal Research, SI(12): 197-209.

Short A D, Wright L D, 1981. Beach systems of the Sydney region. Australian Geographer, 15: 8-16.

Silva P G, Medina R, González M et al., 2018. Infragravity swash parameterization on beaches: The role of the profile shape and the morphodynamic beach state. Coastal Engineering, 136: 41-55.

Stive M J F, Aarninkhof S G J, Hamm L et al., 2002. Variability of shore and shoreline evolution. Coastal Engineering, 47: 211-235.

Veas R, Hernández-Miranda C, Lercari D et al., 2017. Spatial-temporal changes of the morphodynamic beach state before and after the 2010 mega-earthquake and tsunami along south-central Chile. New Zealand Journal of Marine and Freshwater Research, 51(2): 237-253.

Wan Yong, Zhang Jie, Meng Junmin et al., 2015. Wave energy assessment in the East China Sea and South China Sea based on ERA-Interim high resolution data. Acta Energiae Solaris Sinica, 36 (5): 1259-1267. (in Chinese)

Wang Wenjie, Huang Jinsen, Mao Shuzhen, 1991. Coastal and inshore modern sedimentary in South China. Beijing: Science Press. (in Chinese)

Wright L D, Chappell J, Thom B G et al., 1979. Morphodynamics of reflective and dissipative beach and inshore systems, Southeastern Australia. Marine Geology, 50: 105-140.

Wright L D, Short A D, 1984. Morphodynamic variability of surf zones and beaches: A synthesis. Marine Geology, 56: 93-118.

Yu Jitao, Ding Yuanting, Cheng Huangxin et al., 2016. Wave-dominated, mesotidal headland-bay beach morphodynamic classsfications of the Shuidong Bay in South China. Acta Oceanologica Sinica, 35(7): 87-95.

Yu Mugeng, 1984. Analysing the characteristics of wave distribution in the South China Sea on the basis of ship reports. Marine Science Bulletin, 3(4): 1-8. (in Chinese) 